\title{
Short Communication: Cultivation of Lentinus edodes Mycelia Using Whey Permeate as an Alternative Growth Substrate
}

\author{
B. S. Inglet, ${ }^{*}$ M. Song, $†$ C. L. Hansen, ${ }^{*}$ and S. Hwangt ${ }^{1}$ \\ *Department of Nutrition and Food Science, Utah State University, Logan 84322 \\ †School of Environmental Science and Engineering, Pohang University of Science and Technology, \\ Kyungbuk 790-784, Korea
}

\begin{abstract}
The major objective of this research was to use whey permeate as an alternative growth medium for the cultivation of mycelia of the edible mushroom Lentinus edodes and to find an optimum condition for solid-state cultivation. Response surface analysis was applied to determine the combination of substrate concentration (40 to $60 \mathrm{~g}$ of lactose/L), temperature $\left(20\right.$ to $30^{\circ} \mathrm{C}$ ), and $\mathrm{pH}$ (4 to 6) resulting in a maximal mycelial growth rate. The radial extension rates, estimated by measuring the diameters of growing colonies on the Petri dishes, were used as the growth rate of the mycelia at different conditions. The conditions predicted to maximize the mycelial growth of $6.41 \pm 0.47 \mathrm{~mm} / \mathrm{d}$ were determined to be $40 \mathrm{~g}$ of lactose/L, temperature $23.6^{\circ} \mathrm{C}$, and $\mathrm{pH}$ 5.0. It was concluded that a partial cubic equation could accurately model the response surface of, and predict optimal growth conditions for, L. edodes mycelia using whey permeate because the model prediction agreed with the experimental growth rate, $6.39 \pm 0.22 \mathrm{~mm} / \mathrm{d}$. The results suggest that whey permeate could be utilized as a growth substrate for the cultivation of mycelia from the edible mushroom $L$. edodes, enhancing the use of this by-product by the cheese manufacturing industry. Key words: Lentinus edodes, mycelial cultivation, whey permeate
\end{abstract}

The perceived medical benefits, such as antitumor and anti-human immunodeficiency virus, associated with consumption of the mushroom Lentinus edodes have combined with an appealing taste to make it the second most popular edible mushroom in the global market (Hatvani, 2001). Mycelial cultivation has received great interest as an efficient method for industrial production of valuable metabolites because the beneficial bioactive compounds contained in mushrooms can be extracted from the mycelia (Hatvani and Mécs, 2001). Various agro-industrial by-products have

Received July 6, 2005.

Accepted October 26, 2005.

${ }^{1}$ Corresponding author: shwang@postech.ac.kr been used as inexpensive growth substrates for economical production of different mycelial species (Hatvani and Mécs, 2001; Fountoulakis et al., 2002). Whey permeate, rich in carbohydrate (4 to 5\% lactose) and mineral content (González Siso, 1996), can also be considered a growth medium. However, the information regarding the use of whey permeate as a medium for mycelial cultivation is lacking and the efficacy of the biocompounds is directly affected by the culture conditions in which the mycelia were grown (Morais et al., 2002; Lee et al., 2003). Therefore, the purpose of this research was to use whey permeate as a growth medium for mycelia of the mushroom species $L$. edodes, and to find an optimum condition with respect to temperature, $\mathrm{pH}$, and substrate concentration for highest mycelial growth rate under solid-state cultivation.

The experiment was based on a $3 \times 2$ orthogonal design $(\mathrm{pH}$, temperature, and substrate concentration at 2 levels each) with a center point being replicated 5 times, as previously described (Adinarayana et al., 2003; Lee et al., 2003; Table 1). Dried whey permeate powder was dissolved in distilled water to obtain differing concentrations of lactose because the purpose of the research was to provide information about the treatment of raw cheese whey permeate with the mushroom mycelia. Commercial agar (Becton Dickinson and Co., Sparks, MD) was added at the rate of $1.5 \%$ (wt/ vol) and autoclaved at $120^{\circ} \mathrm{C}$ for $20 \mathrm{~min}$. Before pouring the solution into Petri dishes, the $\mathrm{pH}$ was adjusted by addition of $0.5 M \mathrm{HCl}$ or $0.5 M \mathrm{NaOH}$ as needed to meet the independent variables (Table 1 ).

The seed culture of L. edodes (KCTC 6735), obtained from the Korean Collection for Type Culture (KCTC), was transferred to Petri dishes containing potato dextrose agar medium and incubated at $25^{\circ} \mathrm{C}$ for $4 \mathrm{~d}$. Mycelial agar discs $(5 \mathrm{~mm})$ were then cut using a round cutter and used as inocula for subsequent experiments. Because the colonies grow in a circular fashion, the data were collected daily by measuring the diameter of colony in millimeters as it grew on the Petri dish for 10 $d$. The radial extension rates estimated can be assumed equivalent to the growth rate of the mycelia under solidstate cultivation (Sang et al., 2001). Response surface 
a

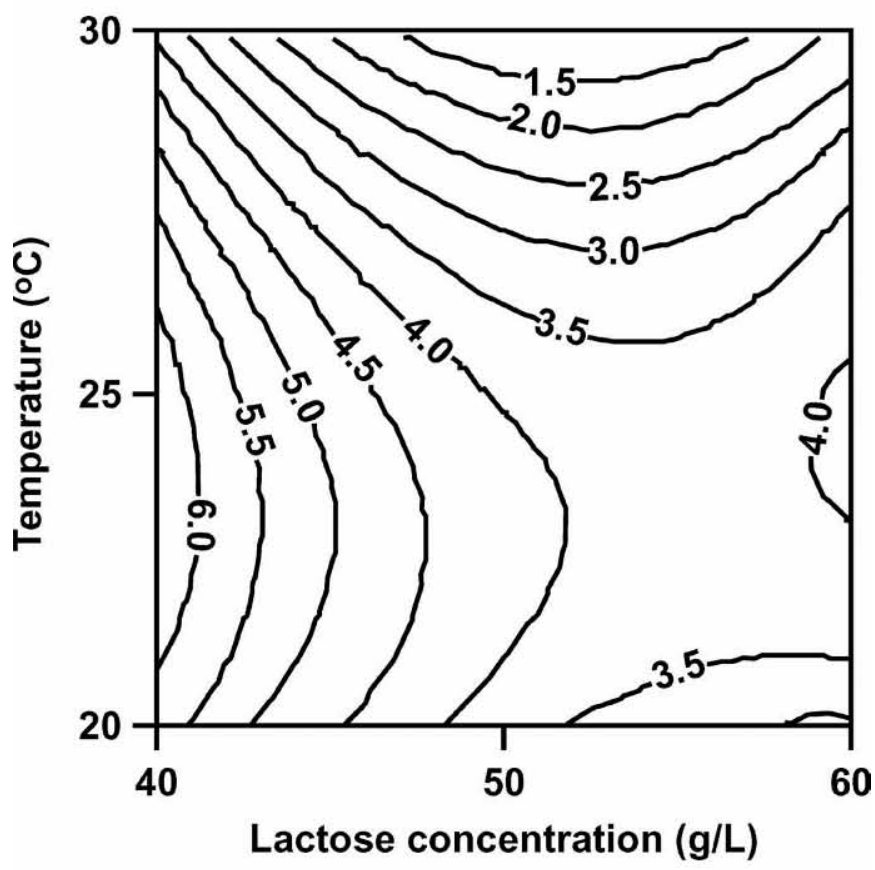

b

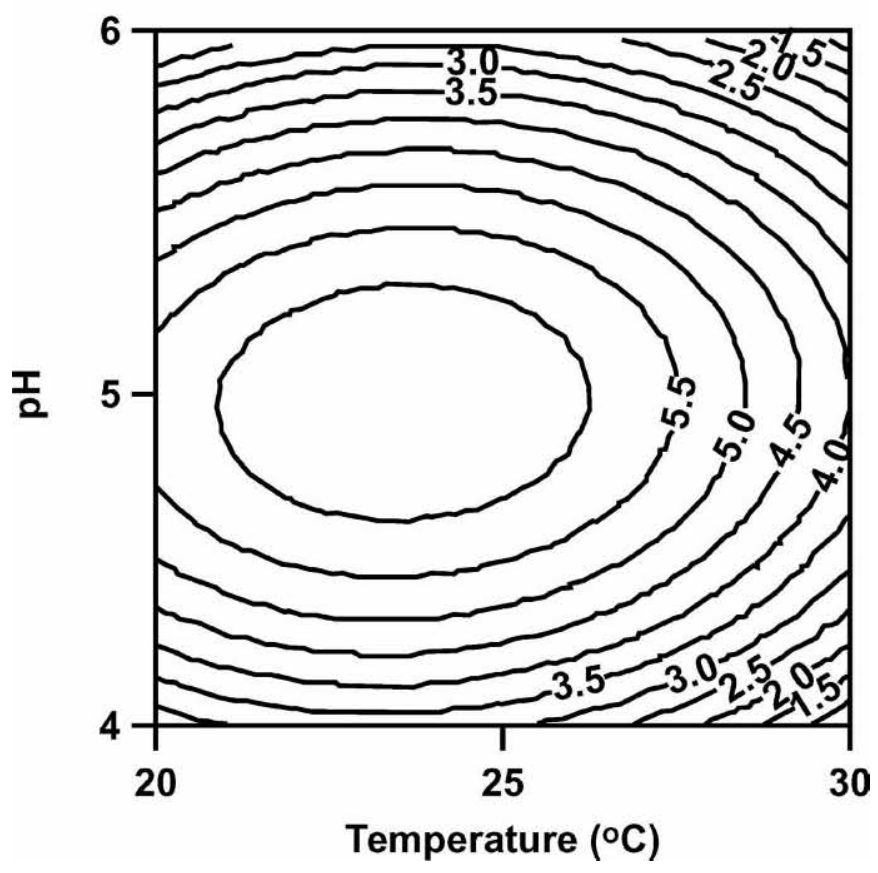

Figure 1. Contour plots of the partial cubic model for mycelial growth of Lentinus edodes with respect to a) temperature and lactose concentration, and b) $\mathrm{pH}$ and temperature.

analysis (RSA) with the corresponding growth conditions was then performed to obtain the set of conditions that would maximize the mycelial growth rate.
For this experiment, ranges of temperature and $\mathrm{pH}$ for growth of $L$. edodes were based on published values. The region of exploration for the RSA was decided as $(4.0,6.0) \mathrm{pH}$ and $(20,30)^{\circ} \mathrm{C}$ because conditions for culturing the mycelia on synthetic media were acidic and slightly mesophilic (Hatvani, 2001; Kim et al., 2002). Because whey permeate has not previously been used for the mycelial cultivation of $L$. edodes, we performed preliminary experiments testing the growth rate of $L$. edodes in various concentrations of whey permeate (i.e., $3,10,20,30,50,70$, and $90 \mathrm{~g}$ of lactose/L). Each trial was cultured in appropriate conditions according to the Korean Collection for Type Culture instructions (i.e., $\mathrm{pH} 5.6$ at $25^{\circ} \mathrm{C}$ ), which were close to the center point of the RSA experiment (i.e., $\mathrm{pH} 5.0$ at $25^{\circ} \mathrm{C}$ ). The substrate concentration that maximized the radial extension rate was determined to be $50 \mathrm{~g} / \mathrm{L}$, which was used as an initial estimate for RSA model building. Therefore, the final ranges of independent variables were decided as $(4.0,6.0) \mathrm{pH},(20,30)^{\circ} \mathrm{C}$, and $(40,60) \mathrm{g}$ of lactose/L. The simultaneous effect of the 3 variables on the mycelial growth was then investigated.

After testing increasingly complex polynomials from linear to partial cubic to model the data with Echip software (version 7.01; Echip Inc., Hockessin, DE), a partial cubic model was selected because the regression coefficient and residual standard deviation of the model were $0.99(P=0.000)$ and 0.16 , respectively. The maximum response was then determined by setting the partial derivatives of the equation to zero with respect to the independent variables. The conditions determined as providing maximal mycelial extension rate, $6.41 \pm$ $0.47 \mathrm{~mm} / \mathrm{d}$, were $40 \mathrm{~g}$ of lactose $/ \mathrm{L}, \mathrm{pH} 5.0$, and temperature $23.6^{\circ} \mathrm{C}$. Because the lactose concentration was not inside the boundary condition, however, additional trials were performed to investigate lactose concentration for the maximal mycelial extension rate was not within the design boundary. A steepest ascent method involving sequential moves in the direction of maximum increase in response (Montgomery and Runger, 1999) was used and the lactose concentration for the mycelial growth rate was a boundary condition.

The individual variables involved in the model were highly significant for mycelial extension rate at the $0.1 \%$ level. The 3 -way interaction of the variables was not significant at the $5 \%$ level $(P=0.115)$, suggesting that all 3 variables were not simultaneously interdependent. Of the 3 possible 2-way interactions among the variables, the interaction between lactose concentration and temperature was significant on the mycelial growth $(P=0.013)$. The interaction between the variables manifests itself in the form of the saddle shape (Figure 1a). This suggests an interaction where the values obtained for lactose concentration and tempera- 
Table 1. Experimental design and observed radial extension rate of Lentinus edodes mycelia grown on reconstituted dry whey permeate

\begin{tabular}{|c|c|c|c|c|c|}
\hline & \multirow[b]{2}{*}{ Trial } & \multicolumn{3}{|c|}{ Independent variables } & \multirow[b]{2}{*}{$\begin{array}{l}\text { Radial } \\
\text { extension } \operatorname{rate}^{1}(\mathrm{~mm} / \mathrm{d})\end{array}$} \\
\hline & & $\begin{array}{l}\text { Lactose } \\
\text { concentration } \\
(\mathrm{g} / \mathrm{L})\end{array}$ & $\begin{array}{l}\text { Media } \\
\mathrm{pH}\end{array}$ & $\begin{array}{l}\text { Incubation } \\
\text { temperature } \\
\left({ }^{\circ} \mathrm{C}\right)\end{array}$ & \\
\hline \multirow[t]{9}{*}{ Linear design } & 1 & 40 & 4 & 20 & $2.6 \pm 0.10$ \\
\hline & 2 & 60 & 4 & 20 & $1.2 \pm 0.08$ \\
\hline & 3 & 40 & 6 & 20 & $1.5 \pm 0.09$ \\
\hline & 4 & 60 & 6 & 20 & $0.8 \pm 0.05$ \\
\hline & 5 & 40 & 4 & 30 & $0.5 \pm 0.01$ \\
\hline & 6 & 60 & 4 & 30 & $0.5 \pm 0.03$ \\
\hline & 7 & 40 & 6 & 30 & $0.3 \pm 0.02$ \\
\hline & 8 & 60 & 6 & 30 & $0.1 \pm 0.01$ \\
\hline & $9^{2}$ & 50 & 5 & 25 & $3.9 \pm 0.20$ \\
\hline \multirow[t]{6}{*}{ Quadratic design } & 10 & 40 & 5 & 25 & $6.3 \pm 0.24$ \\
\hline & 11 & 60 & 5 & 25 & $4.1 \pm 0.13$ \\
\hline & 12 & 50 & 4 & 25 & $6.1 \pm 0.20$ \\
\hline & 13 & 50 & 6 & 25 & $2.5 \pm 0.17$ \\
\hline & 14 & 50 & 5 & 20 & $3.7 \pm 0.15$ \\
\hline & 15 & 50 & 5 & 30 & $1.1 \pm 0.09$ \\
\hline Validation & 16 & 40 & 5 & 23.6 & $6.4 \pm 0.22$ \\
\hline
\end{tabular}

${ }^{1}$ Average value of each trial replicated 5 times.

${ }^{2}$ Center point.

ture will vary based on the values of one another. On the other hand, a clear peak and constant contour lines in the response surface (Figure 1b) indicate that the control variables (i.e., $\mathrm{pH}$ and temperature) are not interdependent.

An additional 5 trials of the experiment were run under the optimal growth conditions predicted by the model to verify the accuracy of the model predictions, which resulted in an average growth rate of $6.39 \pm$ $0.22 \mathrm{~mm} / \mathrm{d}$. Because this experimental growth rate was nearly identical to the model output $(6.41 \pm 0.47 \mathrm{~mm} /$ d), and the standard deviation in the results was small, it is concluded that the model was able to accurately predict optimal growth conditions for L. edodes mycelia using whey permeate as a growth substrate.

\section{ACKNOWLEDGMENTS}

This research was supported in part by the Korean Institute of Environmental Science and Technology (EcoTechnopia-21), and Dairy Management Inc. (National Research Plan, Rosemont, IL) programs.

\section{REFERENCES}

Adinarayana, K., P. Ellaiah, B. Srinivasulu, R. Bhavani Devi, and G. Adinarayana. 2003. Response surface methodological approach to optimize the nutritional parameters for neomycin production by Streptomyces marinensis under solid-state fermentation. Process Biochem. 38:1565-1572.

Fountoulakis, M. S., S. N. Dokianakis, M. E. Kornaros, G. G. Aggelis, and G. Lyberatos. 2002. Removal of phenolics in olive mill wastewaters using the white-rot fungus Pleurotus ostreatus. Water Res. $36: 4735-4744$.

González Siso, M. I. 1996. The biotechnological utilization of cheese whey: A review. Bioresour. Technol. 57:1-11.

Hatvani, N. 2001. Antimicrobial effect of the culture fluid of Lentinus edodes mycelium grown in submerged liquid culture. Int. J. Antimicrob. Agents 17:71-74.

Hatvani, N., and I. Mécs. 2001. Production of laccase and managanese peroxidase by Lentinus edodes on malt-containing by-product of the brewing process. Process Biochem. 37:491-496.

Kim, S. W., H. J. Hwang, J. P. Park, Y. J. Cho, C. H. Song, and J. W. Yun. 2002. Mycelial growth and exo-biopolymer production by submerged culture of various edible mushrooms under different media. Lett. Appl. Microbiol. 34:56-61.

Lee, H., M. Song, and S. Hwang. 2003. Optimizing bioconversion of deproteinated cheese whey to mycelia of Ganoderma lucidum. Process Biochem. 38:1685-1693.

Montgomery, D. C., and G. C. Runger. 1999. Applied Statistics and Probability for Engineers. 2nd ed. Wiley, New York, NY.

Morais, H., C. Ramos, N. Matos, E. Forgács, T. Cserháti, V. Almeida, J. Oliveira, Y. Darwish, and Z. Illés. 2002. Liquid chromatographic and electrophoretic characterisation of extracellular $\beta$ glucosidase of Pleurotus ostreatus grown in organic waste. J. Chromatogr. B. 770:111-119.

Sang, B. I., K. Hori, Y. Tanji, and H. Unno. 2001. A kinetic analysis of the fungal degradation process of poly(3-hydroxybutyrate-co3-hydroxyvalerate) in soil. Biochem. Eng. J. 9:175-184. 